\title{
An application of AHP for students' perspectives on adopting MOOCs
}

\section{Kriti Priya Gupta ${ }^{a^{*}}$}

${ }^{a}$ Symbiosis Centre for Management Studies, NOIDA, Symbiosis International (Deemed University), India

\begin{tabular}{l}
\hline C H R O N I C L E \\
\hline Article history: \\
Received: June 162019 \\
Received in revised format: June \\
192019 \\
Accepted: July 11, 2019 \\
Available online: \\
July 11, 2019 \\
\hline Keywords: \\
Massive Open Online Courses \\
(MOOCs) \\
Analytic Hierarchy Process \\
(AHP) \\
Prioritization
\end{tabular}

\section{A B S T R A C T}

The aim of the present study is to find the relative importance of factors influencing the students' decisions to adopt Massive Open Online Courses (MOOCs). Eight sub-factors categorized under three main factors namely "benefits of MOOCs", "MOOCs features" and "social recognition", are considered for prioritization. The analytic hierarchy process (AHP) methodology is also employed to prioritize the factors. The primary data pertaining to pair-wise comparisons of various factors and sub-factors have been obtained from 250 students by using convenience sampling. The results indicate that academic recognition, followed by openness, autonomy and cost effectiveness of MOOCs are the most important aspects which students consider while deciding to learn through MOOCs.

Prioritization

\section{Introduction}

Online education or e-learning has been a popular form of education which is of interest to those students who cannot pursue full time degree courses. An innovative form of online learning which has recently gained attention is Massive Open Online Courses (MOOCs). MOOCs are provided through various platforms such as coursera, edX, udemy and so on, where courses in cutting edge areas are available (Alraimi et al., 2015). These courses are offered by world-renowned educational institutions. The two core features of MOOCs are massiveness and openness. Massiveness indicates that very large numbers of learners are associated with MOOCs and openness implies that MOOCs do not put any restriction in the form of eligibility criteria on the learners (Anderson, 2013). Therefore, MOOCs are available to all, wherein anyone can access the courses through Internet. Additionally, most of the MOOCs are free of charge barring a few which require some amount to be paid for accessing the course content or for earning the certificate of completion. There are two different formats in which MOOCs are provided. Some of the MOOCs are delivered as per a pre-defined schedule wherein there are set timelines of course initiation and completion. On the other hand, some MOOCs are self-paced wherein the learners have the flexibility of starting the course at any point of time and learning as per their own convenience (Chen, 2013). The learning resources of MOOCs include learning material, reading articles, video lectures, and interactive forums.

\footnotetext{
* Corresponding author.

E-mail address: kriti.gupta@scmsnoida.ac.in (K. P. Gupta) 
Since MOOCs are offered by well-known universities across the globe, they are becoming popular amongst the students especially in developing countries, where access to good quality learning resources is limited (Kennedy, 2014). With their high-quality learning materials on diversified and recent topics, MOOCs can augment the traditional form of education. In developing countries, where full time degrees in recent areas are not available, MOOCs can offer a viable solution to education seekers (Agrawal et al., 2015). Moreover, with their free or low-cost resources, MOOCs offer a cost-effective way of getting education which is an important factor for learners in developing countries (Kennedy, 2014).

Considering the growing potential of MOOCs in developing countries, it is imperative to find out the key factors which students may consider while deciding to choose MOOCs. Though few studies in the past have focused on adoption of MOOCs in developing countries like China (Ma \& Lee, 2019), Pakistan (Khan et al., 2018) and Jordan (Abu-Shanab \& Musleh, 2018), however studies considering the Indian context are lacking. Hence the present study attempts to find the relative importance of factors that influence Indian students' decisions to learn through MOOCs. The study employs the analytic hierarchy process (AHP) as the methodology to prioritize the factors. Application of the AHP methodology distinguishes the present study from the past studies that are based on statistical techniques such as structural equation modeling and regression analysis.

The remaining part of the paper is organized as follows: the next section presents the review of literature on MOOCs adoption, which is followed by the conceptual framework proposed in present study. The subsequent section describes the research method used in the study along with a discussion on AHP. This is followed by data analysis and results wherein the results obtained by applying AHP are presented. Finally, the results are discussed and conclusions are drawn.

\section{Literature Review}

Through a systematic literature review, Hakami et al. (2017) classified the key motivational factors underlying MOOCs adoption into four categories; namely, learner related factors, institution and instructor related factors, platform and course related factors, and facilitating conditions. The learner related factors focus on personal motivations such as academic/job relevance and social influence. The institution and instructor related factors are associated with the reputation of the institution and interaction with the instructor. The platform and course related factors consider the characteristics of the platform and features of the MOOCs including ease of using the platform, openness of MOOCs and ubiquity. Finally, the facilitating conditions include learners' self-efficacy and compatibility with technology (Hakami et al., 2017). Addressing the Indian perspective, Mohapatra and Mohanty (2016) opined that learners' skills, affordability and availability are the key influencers of MOOCs adoption by Indian learners. They also highlighted the importance of reputation of MOOCs providers.

Many studies on adoption of MOOCs have investigated various influential factors based on different theoretical frameworks on technology and innovation adoption. For example, Alraimi et al. (2015) extended the expectation-confirmation theory (ECT) with perceived openness and perceived reputation to explain the MOOCs continuance behavior of learners. Zhou (2016) integrated the theory of planned behavior (TPB) and self-determination theory (SDT) to conceptualize and model of factors that influence the intention to adopt MOOCs in Chinese context. They concluded that attitude towards MOOCs and perceived behavioral control, are significant determinants of MOOCs' adoption intention. Semenova and Rudakova (2016) found that lack of basic subject knowledge, level of education and lack of previous experience with MOOCs were the most important barriers in students' motivation to learn through MOOCs. Abu- Shanab and Musleh (2018) utilized the theory of reasoned action (TRA) and investigated the roles of perceived usefulness, perceived ease of use and social influence in the learners' intent of adopting MOOCs in Jordanian context. The authors found that social influence and perceived usefulness in terms of time and place convenience carry a significant impact on the intention to adopt MOOCs, whereas perceived ease of use does not predict the MOOCs adoption intention. Khan et al. (2018) com- 
bined three frameworks including task-technology-fit (TTF) model, social motivation, and SDT to examine the factors influencing the intention to adopt MOOCs in the context of Pakistan. Their study established a significant contribution of technology and task characteristics in influencing the behavioral intention to adopt MOOCs. They also found that MOOCs' adoption intention was significantly predicted by social recognition, perceived competence and perceived relatedness. Additionally, they opined that perceived reputation of MOOCs provider had a significant moderating effect on the students' usage intention of MOOCs. Sun et al. (2018) explored the antecedents of MOOCs adoption on the basis of SDT and theory of relationship quality. Based on the perceptions of Chinese learners, their results indicated that fulfillment of basic psychological needs namely, relatedness, competence and autonomy, develop intrinsic motivation in learners which in turn increases their psychological engagement in MOOCs. Recently Ma and Lee (2019) presented a model based on technology-user-environment (TUE) framework to investigate the Chinese learners' adoption behavior of MOOCs. They considered perceived usefulness, performance-to-cost value, interactivity, and accessibility under the technology factors; self regulation, experience, and gender, under the user factors; and learning tradition, peers' impact, instruction and publicity, as the social environmental factors within the TUE framework. They concluded that technology factors contribute most toward explanation of MOOCs adoption, followed by user factors and social environmental factors. Specifically, they highlighted that perceived usefulness and performance-to-cost value play a significant role in motivating the students to adopt MOOCs. On the other hand, accessibility barriers such as network accessibility and instruction language barrier, refrain learners from adopting MOOCs (Ma \& Lee, 2019).

Based on the above discussion, it can be said that though quite a few studies have examined the behavior of students in developing countries towards MOOCs, studies highlighting Indian perspective are lacking. Additionally, prior studies have either employed existing technology and innovation acceptance models or borrowed standard constructs from these models to investigate MOOCs adoption or continuance behavior of learners. There is still a need to investigate factors specific to MOOCs, which may drive students' motivation for learning through MOOCs. Further the existing empirical studies have employed statistical techniques such as structural equation modeling or regression analysis to study the impact of various factors on the learners' intention to adopt MOOCs. There is a need to find the relative priorities of the factors which may motivate students to adopt MOOCs.

In order to address the above concerns, the present study proposes a hierarchy of influencing factors of MOOCs adoption and applies the Analytical hierarchy Prosses (AHP) methodology (Saaty, 1980) to prioritize those factors. The study is premised in India to consider the Indian students' perspective which has not been much addressed in the extant literature (Mohapatra \& Mohanty, 2016).

\section{Conceptual Framework}

Based on the extant literature, the present study has identified three main factors that may motivate students to adopt MOOCs, namely benefits of MOOCs, MOOCs features, and social recognition. These factors are further divided into sub-factors as indicated in Fig.1. All the factors along with their sub factors are discussed below:

\subsection{Benefits of MOOCs}

This factor focuses on the advantages of learning trough MOOCs. Prior studies have shown that perceived benefits play a key role in determining users' intention to adopt a technology or innovation (Rogers, 2003). Similarly, in the context of MOOCs, benefits play an important role to motivate learners for studying thorough MOOCs (Hakami \& Chakaveh, 2017). According to Lee (2009), there are two types of benefits of adopting a technology, namely direct benefits and indirect benefits. Direct benefits are tangible whereas indirect benefits are intangible or less tangible (Lee, 2009). For the present study, "benefits" is divided into two tangible benefits namely skill development and knowledge enhancement, and one intangible benefit namely cost effectiveness. 
- Skill development

Calonge and Shah (2016) argued that MOOCs help students in enhancing various skills of students such as thinking skills, time management skills, and communication skills. Unlike in traditional class room learning, students are required to learn in MOOCs, on their own self. This helps in developing problem solving, decision making and self managing skills in students. Hence MOOCs are advantageous for students in terms of skill development.

- Knowledge enhancement

Researchers have argued that if the learners perceive MOOCs to be useful in terms of enhancing their knowledge, then they are more likely to adopt MOOCs (Ma \& Lee, 2019; Wu \& Chen, 2017). Especially in developing countries, where access to good quality learning material is limited, students are inclined towards MOOCs because of their high-quality content in various cutting edge areas (Zhou, 2016).

- Cost effectiveness

Learners especially in developing countries may evaluate the tradeoff between the expenses and value received while learning through MOOCs (Ma \& Lee, 2019; Chou, 2016). Though in most of the MOOCs, learning is free but for earning the certificate of completion, certain fee is charged. However, this fee is less as compared with traditional educational courses. Therefore, cost effectiveness of MOOCs is an important advantage of MOOCs.

\subsection{MOOCs Features}

MOOCs are different from traditional teaching methods because of their unique features such as massiveness, openness, autonomy and associations with renowned academic institutions (Alraimi et al., 2015). These distinguishing features of MOOCs are very valuable for learners which motivate them for studying through MOOCs (Hakami \& Chakaveh, 2017). The present study considers three most prominent features of MOOCs i.e. openness, autonomy and reputation.

- Openness: One of the greatest benefits of MOOCs is their open access to all learners worldwide without any eligibility criteria (Barclay \& Logan, 2013). Since MOOCs are online where teaching-learning is done through Internet, it is a very convenient medium for learners. The content provided by MOOCs can be downloaded by the users, which can be reused at any point of time in future as well. Hence, openness is a very important feature of MOOCs which may motivate learners (Wu \& Chen, 2017; Ma \& Lee, 2019).

- Autonomy: Another important feature of MOOCs is that they provide freedom to the learners to pursue the course as per their convenience (Khan et al., 2018). Since learners can join a MOOC at any point of time and complete it at their own pace, they have the freedom in learning which they lack in tradition teaching methods (Sun et al., 2018). Therefore, autonomy of self-managing the course is an important feature of MOOCs.

- Reputation: The reputation of an educational institution is an important aspect which students consider while deciding to attend that institution (Bourke, 2000). Reputation is a critical determinant of learner's initial assessment of the institution when he or she has no other exposure about that institution. Presently the popular MOOC platforms are associated with highly renowned academic institutions. The credibility and reputation of these institutions is unquestionable. Hence this feature of MOOCs is an important determinant of learners' intention to adopt MOOCs (Wu and Chen, 2017).

\subsection{Social recognition}

Since MOOCs are offered by reputed institutions and are based on assessments including quizzes and assignments, their certificates are valued in the society (Bragg, 2014). The recognition of the MOOCs certificates by the universities and employers develop learners' interest in studying through MOOCs. In the present study, social recognition of MOOCs is divided into two categories viz. academic recognition and industry recognition. 
- Academic recognition: The students who pursue MOOCs along with their regular higher educational degrees are interested in the recognition of MOOCs certificates by their respective universities. The recognition of MOOCs certifications by their universities may attract students for completing MOOCs. If the students get credit adjustments or other rewards from their universities, they would be more likely to complete MOOCs (Wu \& Chen 2017).

- Industry recognition: Though the courses offered through MOOC platforms are of high quality and help learners enhance their knowledge, but if the MOOC certificates are also valued by employers in the industry, then this will be an added advantage for the learners. Recognition of MOOC certificates by the industry increases the employability of learners and hence is an important aspect of MOOCs learning (Khan et al., 2018; Wu \& Chen, 2017).
Level 1: Goal
Level 2: Main
Level 3: Sub-
Factors
Factors

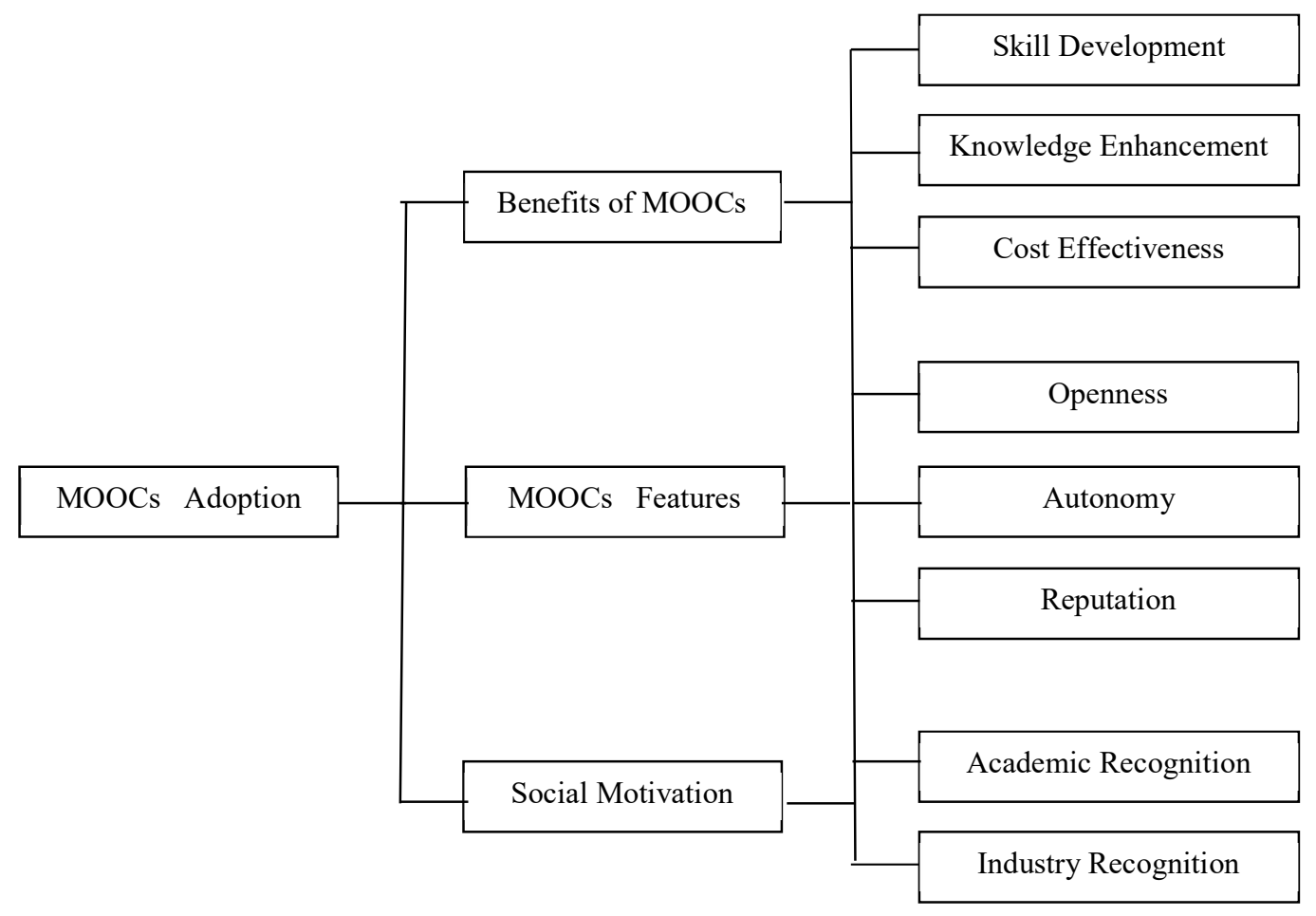

Fig. 1: The AHP Hierarchy

\section{Research Method}

The present study employs the AHP methodology which is a multi-criteria decision making (MCDM) technique. AHP approach has been used by many researchers for prioritizing influencing factors in various contexts. For example, Green and Ramroop (2014) applied AHP for prioritizing factors influencing service quality of a university. Sadeghi et al. (2013) found the effective factors for organizational readiness in executing knowledge management, by using AHP. Gupta et al. (2017) employed AHP to find the relative importance of factors influencing adoption of e-government. Gupta and Chaudhary (2017) prioritized the factors influencing whistle-blowing intention of teachers in higher education sector. As recommended by Saaty (1980), the first step in AHP is to break down the decision problem into a hierarchy consisting of at least three levels: goal, criteria, and alternatives. For the present study, the decision problem is to prioritize the factors that influence the adoption of MOOCs. The problem is broken down into a hierarchy consisting of three levels as indicated in Fig.1. The first level represents the goal which is "to prioritize the factors underlying adoption of MOOCs"; the second level represents the main factors (or criteria) that influence the MOOCs adoption; and the third level represents the sub-factors (or sub-criteria) categorized under the main factors. Since the present problem is confined to prioritization of factors 
only, therefore there are no decision alternatives in the AHP hierarchy. After building the AHP hierarchy, data pertaining to pair-wise comparisons of various factors and sub-factors is required for calculating the priorities (or weights) of the factors (Saaty, 1980). For the present study, data was collected from 250 students who were familiar with MOOCs. The students were selected using convenience sampling from 5 universities in the National Capital Region (NCR) of Delhi, India. A structured questionnaire consisting of questions on pair-wise comparisons of factors was used to collect the data (see Annexure A). The comparisons were captured using Saaty's nine-point scale of relative importance (see table 1). While administering the questionnaires, the respondents were briefed about the purpose of the study, the description of the factors and the response format. The sample comprised of $30.7 \%$ females and $69.3 \%$ males. The average age of the respondents was 18.3 years, with standard deviation 1.4 years. $65 \%$ students were studying at graduate level whereas $35 \%$ respondents were pursuing post graduate courses.

Table 1

Scale of Relative Importance

\begin{tabular}{clll}
\hline $\begin{array}{c}\text { Intensity of } \\
\text { Importance }\end{array}$ & Definition & $\begin{array}{l}\text { Intensity of } \\
\text { Importance }\end{array}$ & Definition \\
\hline 1 & Equal Importance & 7 & Very Strong Importance \\
3 & Moderate Importance & 9 & Extremely Strong Importance \\
5 & Strong Importance & $2,4,6,8$ & Intermediate Values (For compromise between the above values) \\
\hline
\end{tabular}

After collecting the data, the weights of all the factors and sub-factors were determined by using steps described in the next section.

\section{Data Analysis and Results}

On the basis of the collected data, comparison matrices were obtained for each respondent. As there were 250 respondents, 250 comparison matrices were made for comparing main factors with each other; 250 matrices were made for comparing the sub-factors of the main factor "benefits of MOOCs"; 250 matrices were made for comparing the sub-factors of the main factor "MOOCs features"; and 250 matrices were made for comparing the sub-factors of the main factor "social recognition". The matrices of individual respondents were then aggregated using geometric mean method (Saaty, 1980; Forman \& Peniwati, 1998) to obtain four comparison matrices as indicated in Tables 2-5. As can be seen, all the comparison matrices are reciprocation.

\section{Table 2}

Comparison matrix for comparing the main factors

\begin{tabular}{lccc}
\hline & Benefits of MOOCs & MOOCs features & \multicolumn{2}{c}{ Social recognition } \\
\hline Benefits of MOOCs & 1.00 & 0.15 & 0.20 \\
MOOCs features & 6.46 & 1.00 & 0.63 \\
Social recognition & 4.93 & 1.59 & 1.00 \\
\hline
\end{tabular}

Table 3

Comparison matrix for comparing the sub-factors of "benefits of MOOCs"

\begin{tabular}{lccc}
\hline & Skill development & Knowledge enhancement & Cost effectiveness \\
\hline Skill development & 1.00 & 0.20 & 0.12 \\
Knowledge enhancement & 4.93 & 1.00 & 0.32 \\
Cost effectiveness & 8.28 & 3.11 & 1.00 \\
\hline
\end{tabular}

\section{Table 4}

Comparison matrix for comparing the sub-factors of "MOOCs features"

\begin{tabular}{lccc}
\hline & Openness & Autonomy & Reputation \\
Openness & 1.00 & 4.12 & 7.23 \\
Autonomy & 0.24 & 1.00 & 3.17 \\
Reputation & 0.14 & 0.31 & 1.00 \\
\hline
\end{tabular}


Table 5

Comparison matrix for comparing the sub-factors of "social recognition"

\begin{tabular}{lcc}
\hline & Academic recognition & Industry recognition \\
\hline Academic recognition & 1.00 & 3.30 \\
Industry recognition & 0.30 & 1.00 \\
\hline
\end{tabular}

The matrices were then normalized by dividing each element in a matrix by respective column sum. Then the weights or priorities were calculated by averaging the elements of rows in normalized matrices (Saaty, 1980). Then, the consistencies of all the comparison matrices were checked in order to ensure the acceptability of the weights. The following steps were used to check the consistencies:

Step 1: Calculate $\lambda_{\max }$ by solving the following equation where $\mathrm{A}$ is the comparison matrix and $\mathrm{W}$ is the matrix of weights:

$$
A W=\lambda_{\max } W
$$

Step 2: Calculate the consistency index by using the following formula, where $\mathrm{n}$ is the number of factors within the comparison matrix:

$$
C I=\frac{\lambda_{\max }-n}{n-1}
$$

Step 3: Calculate consistency ratio (CR) by using the following formula:

$$
C R=\frac{C I}{R I}
$$

Here, RI is a random index which is obtained from Saaty's table of random index (see Table 6) corresponding to a particular value of $n$.

\begin{tabular}{|c|c|c|c|c|c|c|c|c|c|c|c|c|c|}
\hline $\mathrm{n}$ & 1 & 2 & 3 & 4 & 5 & 6 & 7 & 8 & 9 & 10 & 11 & 12 & 13 \\
\hline RI & 0 & 0 & 0.58 & 0.90 & 1.12 & 1.24 & 1.32 & 1.41 & 1.45 & 1.49 & 1.51 & 1.58 & 1.56 \\
\hline
\end{tabular}

\section{Table 6}

Table of Random Index (Saaty, 1980)

Tables 7-10 depict the weights and results of consistency tests for all the comparison matrices. It can be noted that the CR for all the matrices is less than 0.10 which indicates that all the comparison matrices are consistent (Saaty, 1980). Therefore, the weights obtained are acceptable.

Table 7

Analysis of the main factors

\begin{tabular}{lcc}
\hline & Weights & Consistency test \\
\hline Benefits of MOOCs & 0.08 & $\lambda_{\max }=3.06$ \\
MOOCs features & 0.41 & $\mathrm{CI}=0.03$ \\
Social recognition & 0.51 & $\mathrm{RI}=0.58 \quad \mathrm{CR}=0.05<.10$ \\
\hline
\end{tabular}

\section{Table 8}

Analysis of the sub-factors of "benefits of MOOCs"

\begin{tabular}{lcc}
\hline & Weights & Consistency test \\
\hline Skill development & 0.07 & $\lambda_{\max }=3.04$ \\
Knowledge enhancement & 0.27 & $\mathrm{CI}=0.03$ \\
Cost effectiveness & 0.67 & $\mathrm{RI}=0.58 \mathrm{CR}=0.04<.10$ \\
\hline
\end{tabular}

Table 9

Analysis of the sub-factors of "MOOCs features"

\begin{tabular}{lcc}
\hline & Weights & Consistency test \\
\hline Openness & 0.71 & $\lambda_{\max }=3.04$ \\
Autonomy & 0.21 & $\mathrm{CI}=0.02$ \\
Reputation & 0.08 & $\mathrm{RI}=0.58 \mathrm{CR}=0.03<.10$ \\
\hline
\end{tabular}


Table 10

Analysis of the sub-factors of "social recognition"

\begin{tabular}{lcc}
\hline & Weights & Consistency test \\
\hline Academic recognition & 0.77 & $\lambda_{\max }=2.00$ \\
Industry recognition & 0.08 & $\mathrm{CI}=0.00 \quad \mathrm{RI}=0.00 \mathrm{CR}=0.00<.10$ \\
\hline
\end{tabular}

Apart from the local weights within the factors and sub-factors, the global weights were also calculated, as indicated in Table 11.

Table 11

Local and global weights

\begin{tabular}{|c|c|c|c|c|c|}
\hline Main factors & Weights & Sub-factors & Local & Global & Overall rank \\
\hline \multirow{3}{*}{$\begin{array}{l}\text { Benefits of } \\
\text { MOOCs }\end{array}$} & \multirow{3}{*}{0.08} & Skill development & 0.07 & 0.01 & 8 \\
\hline & & Knowledge enhancement & 0.27 & 0.02 & 7 \\
\hline & & Cost effectiveness & 0.67 & 0.05 & 4 \\
\hline \multirow{3}{*}{$\begin{array}{l}\text { MOOCs } \\
\text { features }\end{array}$} & \multirow{3}{*}{0.41} & Openness & 0.71 & 0.29 & 2 \\
\hline & & Autonomy & 0.21 & 0.09 & 3 \\
\hline & & Reputation & 0.08 & 0.03 & 6 \\
\hline \multirow{2}{*}{$\begin{array}{l}\text { Social } \\
\text { recognition }\end{array}$} & \multirow{2}{*}{0.51} & Academic recognition & 0.77 & 0.39 & 1 \\
\hline & & Industry recognition & 0.08 & 0.04 & 5 \\
\hline
\end{tabular}

\section{Discussion}

The results indicate that the within the main factors, "social recognition" is considered to be the most important factor (weight $=0.51$ ) by the students for adopting MOOCs. This is followed by the factors "MOOCs features" (weight $=0.41$ ) and "benefits of MOOCs" (weight $=0.08$ ). This indicates that students are primarily concerned about the recognition of the courses offered through MOOC platforms. If they believe that MOOCs certificates are well recognized and carry significant value, then they will be motivated to pursue MOOC programs. As indicated by the results, the features of MOOCs also attract students. As MOOCs are different from traditional teaching methods, in the sense that there no deadlines and restrictions in pursuing these courses, students get attracted towards learning through MOOCs. The benefits of MOOCs are found to be least important amongst all the three factors. This indicates that students are not much influenced by the tangible or intangible benefits of MOOCs; they consider the recognition and features of MOOCs to be the deciding factors for adopting MOOCs.

Within the factor "social recognition", academic recognition is more valued by the students (weight $=0.77$ ) than the industry recognition (weight $=0.08$ ). This indicates that students are more interested in getting recognition in the form of credit benefits from their respective universities rather than getting recognition from the industry. Within the factor "MOOCs features", openness (weight $=0.71$ ) is considered to be most important followed by autonomy (weight $=0.21$ ) and reputation (weight $=0.08$ ). Though "benefits of MOOCs" is found to be least important, but within this factor, cost effectiveness is emerged to be the most important aspect with a very strong importance (weight $=0.67$ ), which is followed by knowledge enhancement (weight $=0.27$ ) and skill development (weight $=0.07$ ).

Considering the global weights or overall ranks of all the sub-factors, it can be noticed that academic recognition (global weight $=0.39$ ), followed by openness (global weight $=0.29$ ), autonomy (global weight $=0.09$ ), and cost effectiveness (global weight $=0.05$ ) are the most important aspects which students consider while deciding to learn through MOOCs. This implies that students wish to adopt MOOCs if they get recognition for the certificates awarded by MOOCs. They are also influenced by the fact that MOOCs are open to anyone without any eligibility restrictions and give them flexibility of learning at their own pace and convenience. Since the students are value conscious, they also get influenced by the expenses incurred in MOOCs. If they find that MOOCs are offered at a reasonable price by well known and reputed universities, they get inclined towards taking such courses. 


\section{Conclusion}

The aim of the present study was to find the relative importance of factors influencing the students' decisions to adopt MOOCs. Eight sub-factors categorized under three main factors were considered for prioritization. The AHP methodology was employed to prioritize the factors. The results indicate that students wish to pursue only those MOOCs which are recognized by their universities. Moreover, openness of MOOCs wherein the students can manage the learning as per their convenience is an attractive feature for students. The study has provided few practical implications for various stakeholders. Firstly, the academic institutions should recognize the MOOC certificates and provide support to their students in the form of credit transfers or other rewards. Secondly, the MOOC providers should also focus on developing self-paced courses in cutting edge areas with affordable prices. The study has employed AHP methodology which could not consider the interrelationships amongst the factors considered. Future studies may employ the analytic network process (ANP) consider the interdependence of the factors for calculating the relative priorities. Moreover, the study was based on the perceptions of students who were pursuing some regular full-time degree programs. Future studies may consider the perceptions of general learners who are employed and want to learn through MOOCs.

\section{References}

Abu-Shanab, E. A., \& Musleh, S. (2018). The Adoption of Massive Open Online Courses: Challenges and Benefits. International Journal of Web-Based Learning and Teaching Technologies (IJWLTT), 13(4), 62-76.

Agrawal, A., Kumar, A., \& Agrawal, P. (2015). Massive open online courses: EdX. org, Coursera. com and NPTEL, a comparative study based on usage statistics and features with special reference to India, 390-402.

Anderson, T. (2013). Promise and/or peril: MOOCs and open and distance education. Commonwealth of learning, 3, 1-9.

Alraimi, K. M., Zo, H., \& Ciganek, A. P. (2015). Understanding the MOOCs continuance: The role of openness and reputation. Computers \& Education, 80, 28-38.

Barclay, C., \& Logan, D. (2013, December). Towards an understanding of the implementation \& adoption of massive online open courses (MOOCs) in a developing economy context. In Proceedings Annual Workshop of the AIS Special Interest Group for ICT in Global Development (Vol. 6, pp. 1-14).

Bourke, A. (2000). A model of the determinants of international trade in higher education. Service Industries Journal, 20(1), 110-138.

Bragg, A. B. (2014). MOOCs: Where to from here?. Training \& Development, 41(1), 20.

Calonge, D., \& Shah, M. (2016). MOOCs, graduate skills gaps, and employability: A qualitative systematic review of the literature. The International Review of Research in Open and Distributed Learning, 17(5), 67-90.

Chen, S. (2015). The research of English massive open online course based on virtual technology. Computer Modelling \& New Technologies, 19, 79-82.

Forman, E., \& Peniwati, K. (1998). Aggregating individual judgments and priorities with the analytic hierarchy process. European journal of operational research, 108(1), 165-169.

Gupta, K. P., \& Chaudhary, N. S. (2017). Prioritizing the Factors influencing Whistle Blowing Intentions of Teachers in Higher Education Institutes in India. Procedia Computer Science, 122, 25-32.

Gupta, K. P., Bhaskar, P., \& Singh, S. (2017). Prioritization of factors influencing employee adoption of e-government using the analytic hierarchy process. Journal of Systems and Information Technology, 19(1/2), 116137.

Green, P., \& Ramroop, S. (2014). Prioritising factors influencing service quality at Durban University of Technology: AHP Approach. Journal of Social Sciences, 40(2), 243-250.

Hakami, N., White, S., \& Chakaveh, S. (2017). Motivational Factors that Influence the use of MOOCs: Learners' Perspectives. In Proceedings of the 9th International Conference on Computer Supported Education (CSEDU 2017) (pp. 323-331).

Kennedy, J. (2014). Characteristics of massive open online courses (MOOCs): A research review, 20092012. Journal of Interactive Online Learning, 13(1).

Khan, I. U., Hameed, Z., Yu, Y., Islam, T., Sheikh, Z., \& Khan, S. U. (2018). Predicting the acceptance of MOOCs in a developing country: Application of task-technology fit model, social motivation, and self-determination theory. Telematics and Informatics, 35(4), 964-978. 
Lee, M. C. (2009). Factors influencing the adoption of internet banking: An integration of TAM and TPB with perceived risk and perceived benefit. Electronic commerce research and applications, 8(3), 130-141.

Ma, L., \& Lee, C. S. (2019). Investigating the adoption of MOOC s: A technology-user-environment perspective. Journal of Computer Assisted Learning, 35(1), 89-98.

Mohapatra, S., \& Mohanty, R. (2017). Adopting MOOCs for afforable quality education. Education and information technologies, 22(5), 2027-2053.

Rogers, E. M. (2003). Diffusion of innovations. New York, NY: Free Press.

Saaty, T. L. (1980). The analytic Hierarchy Process. McGrawHill international. New York, NY, USA.

Sadeghi, R. M., Mohammad Moghimi, S., \& Ramezan, M. (2013). Identifying and prioritizing of effective constructs in readiness of knowledge management implementation by using fuzzy analytic hierarchy process (AHP). Journal of knowledge-based Innovation in China, 5(1), 16-31.

Semenova, T. V., \& Rudakova, L. M. (2016). Barriers to taking massive open online courses (MOOCs). Russian Education \& Society, 58(3), 228-245.

Sun, Y., Ni, L., Zhao, Y., Shen, X. L., \& Wang, N. (2018). Understanding students' engagement in MOOCs: An integration of self-determination theory and theory of relationship quality. British Journal of Educational Technology.

Wu, B., \& Chen, X. (2017). Continuance intention to use MOOCs: Integrating the technology acceptance model (TAM) and task technology fit (TTF) model. Computers in Human Behavior, 67, 221-232.

Zhou, M. (2016). Chinese university students' acceptance of MOOCs: A self-determination perspective. Computers \& Education, 92, 194-203.

\section{Appendix A: Questionnaire for pair-wise comparisons}

\section{Comparisons among main factors}

\begin{tabular}{|l|l|l|l|l|l|l|l|l|l|l|l|l|l|l|l|l|l|l|}
\hline Factor 1 & 9 & 8 & 7 & 6 & 5 & 4 & 3 & 2 & 1 & 2 & 3 & 4 & 5 & 6 & 7 & 8 & 9 & Factor 2 \\
\hline Benefits of MOOCs & & & & & & & & & & & & & & & & & & MOOCs features \\
\hline Benefits of MOOCs & & & & & & & & & & & & & & & & & & Social recognition \\
\hline MOOCs features & & & & & & & & & & & & & & & & & & Social recognition \\
\hline
\end{tabular}

\section{Comparisons among sub factors of "Benefits of MOOCs"}

\begin{tabular}{|l|l|l|l|l|l|l|l|l|l|l|l|l|l|l|l|l|l|l|}
\hline Factor 1 & 9 & 8 & 7 & 6 & 5 & 4 & 3 & 2 & 1 & 2 & 3 & 4 & 5 & 6 & 7 & 8 & 9 & Factor 2 \\
\hline Skill development & & & & & & & & & & & & & & & & & $\begin{array}{l}\text { Knowledge enhance- } \\
\text { ment }\end{array}$ \\
\hline Skill development & & & & & & & & & & & & & & & & & Cost-effectiveness \\
\hline $\begin{array}{l}\text { Knowledge enhance- } \\
\text { ment }\end{array}$ & & & & & & & & & & & & & & & & & & Cost-effectiveness \\
\hline
\end{tabular}

Comparisons among sub factors of "MOOCs features"

\begin{tabular}{|l|l|l|l|l|l|l|l|l|l|l|l|l|l|l|l|l|l|l|}
\hline Factor 1 & 9 & 8 & 7 & 6 & 5 & 4 & 3 & 2 & 1 & 2 & 3 & 4 & 5 & 6 & 7 & 8 & 9 & Factor 2 \\
\hline Openness & & & & & & & & & & & & & & & & & Autonomy \\
\hline Openness & & & & & & & & & & & & & & & & & & Reputation \\
\hline Autonomy & & & & & & & & & & & & & & & & & & Reputation \\
\hline
\end{tabular}

Comparisons among sub factors of "Social recognition"

\begin{tabular}{|l|l|l|l|l|l|l|l|l|l|l|l|l|l|l|l|l|l|l|}
\hline Factor 1 & 9 & 8 & 7 & 6 & 5 & 4 & 3 & 2 & 1 & 2 & 3 & 4 & 5 & 6 & 7 & 8 & 9 & Factor 2 \\
\hline Academic recognition & & & & & & & & & & & & & & & & & & Industry recognition \\
\hline
\end{tabular}

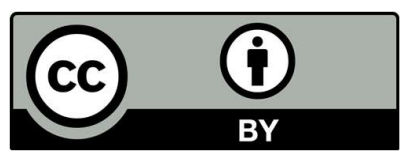

(C) 2019 by the authors; licensee Growing Science, Canada. This is an open access article distributed under the terms and conditions of the Creative Commons Attribution (CCBY) license (http://creativecommons.org/licenses/by/4.0/). 